\title{
Review on Different-Different TLBO Methods in Data Mining
}

\author{
Trupti Ayachit ${ }^{1}$, Amit Sariya ${ }^{2}$ \\ Student, Computer Science and Engineering, Alpine Institute of Technology, Ujjain, India ${ }^{1}$ \\ Assistant Professor, Computer Science and Engineering, Alpine Institute of Technology, Ujjain, India ${ }^{2}$
}

\begin{abstract}
Data mining is the process of extracting useful information from this flooded data, which helps in making profitable future decisions in these fields. Evolutionary Algorithms (EA) are generic meta-heuristic optimization algorithms that use techniques inspired by nature's evolutionary processes. EA maintains a whole set of solutions that are optimized at the same time instead of a one single solution. The inherent randomness of the emulated biological processes enables them to provide good approximate solutions nevertheless. The recently emerged nature-inspired multi-objective meta-heuristic optimization algorithms Teaching Learning-Based Optimization (TLBO) and its variations Elitist TLBO belong to this category. Both these algorithms aim to find global solutions for real world problem with less computational effort and high reliability. The principle idea behind TLBO is the simulation of teaching-learning process of a traditional classroom in to algorithmic representation with two phases called teaching and learning. Elitist TLBO was pioneered with a major modification to eliminate the duplicate solutions in learning phase. In this paper, we have studied about different-different efficient algorithm of TLBO that was designed. Also, a brief study has given about TLBO phases and comparison.
\end{abstract}

Keywords: Data Mining, TLBO, Elitist TLBO, TLBO phases, Elitist TLBO algorithms

\section{INTRODUCTION}

Data mining, the extraction of hidden predictive information from large databases, is a powerful new technology with great potential to help user focus on the most important information in their data warehouses [1].

An extensive variety of optimization algorithms arrive in swarm insight and developmental calculation writing like Genetic Algorithm (GA), Particle Swarm Optimization (PSO), Artificial Bee Colony (ABC), Ant Colony Optimization (ACO), Harmony Search(HS), the Grenade Explosion Method(GEM), and so forth are a couple of them. GA utilizes the Darwinian hypothesis of development in light of the survival of the fittest [2], PSO actualizes the seeking for the conduct of a herd of birds or a school of fish for searching food [3], ABC mimics the scouring conduct of a honeybee[4], ACO takes a shot at depicting the conduct of an ant searching for a destination from the source [5], HS works away at the guideline of music extemporization by a gathering of music players [6] and GEM takes a shot at the standard of the blast of a grenade. As of late, another optimization algorithm known as TLBO [7] in view of the idea of classroom teaching scenario was proposed by Rao etal. It soon turned into a prevalent tool for tackling global optimization issues in view of a few alluring components like free from the algorithm-particular parameters, (i.e.no algorithm-specific parameters are required for the working of the algorithm), ease in programming, productivity and so on. The fundamental standard on which TLBO works lies in the effect of an educator on the output of learners (students) in a class. The execution of a learner is measured by the outcomes or grades which student (he/she) gets. The teacher plays the part of knowledge supplier [8]. A superior teacher produces superior information to the student. It is evident that a good teacher trains learner such that they can have better results regarding the imprints or reviews. TLBO has been connected to tackle diverse optimization issues adequately and productively.

\section{LITERATURE SURVEY}

TLBO algorithm for shape and estimate optimization of truss structures with Dynamic frequency requirements by A. Baghlani, et. al. has been proposed to take care of the optimization issue. The entangled issue of truss shape and optimization with various frequency requirements is researched in this paper. Different benchmark issues are comprehended with this strategy and the outcomes are contrasted and those found by different systems including Metaheuristics, for example, PSO, HS and FA. In all experiments, the outcomes demonstrate that TLBO prompts exceptionally tasteful results i.e. lighter structures which fulfil all frequency imperatives. The consequences of this study demonstrate brilliant innate limit of the methodology in managing muddled dynamic non-linear optimization problems[9]. 


\section{International Journal of Advanced Research in Computer and Communication Engineering}

Vol. 8, Issue 2, February 2019

TLBO Algorithm for Dealing with Real-Parameter Optimization Problems by Kailin Wang et. al. has worked concerning TLBO from the logarithmic and expository perspectives. Thus, in this paper ideas and algorithms of TLBO then study the running component of TLBO for managing the genuine parameter optimization issues, lastly amass its certifiable applications with a sorting system in view of the grouping, multi-objective optimization, parameter optimization, and structure optimization have been examined. The principle point of preference of this work is to offer the clients some assistance with employing TLBO without knowing subtle elements of this algorithm. An exploratory correlation for showing the viability of TLBO on 5 benchmark assessment capacities have additionally been performed[10].

ETLOBA for Global Optimization by Anguluri Rajasekhar et. al. has proposed another variation of TLBO termed as ETLOBA has been proposed for numerical capacity improvement. The proposed technique is engaged with two mechanisms to achieve the exact global optimum with less time multifaceted nature. One of them is elitism, which fortifies the capacity of advancement system by holding the best arrangement acquired in this way, then again Opposition strategy helps in enhancing the ability of looking. As ETLOBA had favourable position of both Elitism and Opposition based learning, henceforth it tries to get ideal arrangements with ensured union. the outcomes acquired by ETLOBA are been contrasted and new state-of-art optimizationmethods like ABC, HS and so on., demonstrates the predominance of the proposed approach in tackling consistent optimization problems [11].

The majority of the diverse ways to deal with the issue of clustering analysis are for the most part in view of factual, neural network, machine learning methods. Bagirov et al. propose the global optimization way to deal with grouping and exhibit how the administered data order issue can be comprehended through bunching. The target capacity in this issue is both nonsmoothed and nonconvex and has an expansive number of local minimizers. Because of countless and the many-sided quality of the goal capacity, broadly useful global optimization strategies, when in doubt neglect to take care of such issue. It is imperative along these lines, to create optimization algorithm that permit the chief to discover "deep" local minimizers of the goal capacity. Such profound minimizers give an adequate portrayal of the data set under thought similarly as grouping is concerned [12].

Weighted Teaching-Learning-Based Optimization for Global Function Optimization by Suresh Chandra Satapathy, Anima Naik, K. Parvathi have proposed an enhanced rendition of TLBO algorithm,called the WTLBO. This algorithm utilizes a parameter as a part of TLBO algorithm to build union rate. Execution correlations of the proposed strategy are provided against the first TLBO and some other exceptionally prevalent and intense transformative algorithms. The weighted TLBO (WTLBO) algorithm on a few benchmark optimization issues demonstrates a stamped change in execution over the customary TLBO and different algorithms also. The proposed approach, known as Weighted-TLBO (WTLBO) depends on the characteristic wonders of human brain (a learner's brain) in forgetting the lessons learnt in last session. The paper recommended an incorporation of a parameter known as "weight" to address this phenomenon while utilizing the learning mathematical statement as a part of teaching and learning phases of fundamental TLBO algorithm.In spite of the fact that, incorporation of a parameter, for example, weight may appear to expand the unpredictability of the essential TLBO algorithm while tuning the parameter, the recommended approach in the work in setting up the weight parameter facilitates the undertaking and ready to give better results contrasted with fundamental TLBO and all other explored algorithms in this work for a few benchmark capacities. The proposed WTLBO is ready to discover global optima results as well as does in quicker calculation time [13].

Be that as it may, Waghmare in [14] remarked on the work of $\mathrm{C}^{\sim}$ repinšek et al. He not just tended to the questions raised by $\mathrm{C}^{\sim}$ repinšek et al. be that as it may, likewise revaluated the exploratory results, which exhibits that the TLBO calculation performs well on the issues where the wellness separation relationships are low by appropriate tuning of the regular control parameters of the calculation and remedied the comprehension about the TLBO algorithm in an objective manner.TLBO has been utilized by number of researchers to take care of their issues and thought that it was successful than another Metaheuristic.

Krishnanand et al. in [15] have connected a multi-objective TLBO algorithm with non- domination-based sorting to settle the environmental or economic dispatch (EED) issue containing the incommensurable goals of best monetary dispatch and minimum outflow dispatch.

Rao and Patel in [16] investigated the utilization of TLBO and ABC algorithms for deciding the ideal working states of consolidated Brayton and reverse Brayton cycles.

Rao et al. in [17] proposed the optimization of mechanical configuration issues utilizing TLBO and tried it on five distinctive compelled benchmark test capacities with various characteristics, four diverse benchmark mechanical outline issues and six mechanical outline optimization issues. 
Vol. 8, Issue 2, February 2019

Rajasekhar et al. in [18] proposed another variation of TLBO, termed as ETLOBA Algorithm for numerical capacity streamlining, which is engaged with two components, one is elitism and second is Opposition technique (enhances the ability of looking), to achieve the precise worldwide ideal with less time multifaceted nature.

\section{ELITIST TLBO ALGORITHM}

Elitist TLBO algorithm is additionally proposed by R. V. Rao in 2012. The idea of elitism is used in the first TLBO algorithm to distinguish the impact on investigation and misuse limit of TLBO algorithm, where amid each era the most exceedingly awful arrangements are supplanted by the tip top arrangements. In Elitist TLBO, the copy arrangements are adjusted by transformation on haphazardly chosen measurements of the copy arrangements before executing the cutting edge. Additionally, the impact of the normal controlling parameters of the algorithm, i.e., populace size, number of eras and tip top size on the execution of the algorithm are likewise explored by considering distinctive populace sizes, number of generations and elite sizes.

\section{A. Teaching Learning Based Optimization (TLBO)}

Teaching-learning is a critical procedure where everyone tries to take in something from different people to enhance themselves. Rao et al. [19,20] and Rao and Patel [21] proposed an algorithm known as TLBO, which reenacts the conventional teaching learning phenomenon of a classroom. The algorithm reproduces two principal methods of learning: (i) through the teacher (known as the teacher phase) and (ii) cooperating with different learners (known as the learner phase). TLBO is a populace based algorithm, where a gathering of students (i.e. learner) is viewed as the populace and the diverse subjects offered to the learners are undifferentiated from with the distinctive outline variables of the optimization problem. The aftereffects of the learner are similar to the wellness estimation of the optimization problem.

In the following subsections, how the different functions of TLBO work, how we have parallelized them, and discuss the intricacies involved in are mentioned in the paper.

- Initialize_Population

- $\quad$ Calculate_Fitness

- Calculate_Mean_Vector

- Best_Solution

- $\quad$ Create_New_Population

- Compare_Fitness

B. Improved Teaching Learning Based Optimization (iTLBO)

In the customary TLBO, the teacher phase makes the algorithm continues by moving the mean of the learners towards it learners where as iTLBO tries to get another arrangement of enhanced learners by shaping an arbitrary weighted differential vector the present mean and the wanted mean and it is added to the current populace of learners. The learner phases the algorithms continue in the comparable route by association among learners enhance his or her insight. To acquire another arrangement of enhanced learners an irregular weighted differential vector is framed from a given learner $\mathrm{Xg}(\mathrm{i})$ another learner $\mathrm{Xg}(\mathrm{r})$ is arbitrarily chosen $(\mathrm{i} \neq \mathrm{r})$ and added to the leaving learner[22].

In this algorithm it is proposed to change this arbitrary weighted differential vector in an irregular way in the extent $(0.5,1)$ by utilizing the connection

$$
0.5 *(1+\operatorname{rand}(0,1))
$$

Where, rand $(0,1)$ is a consistently disseminated irregular number inside of the range $[0,1]$.

So, the mean estimation of this weighted differential scale element is 0.75 . This takes into account indeterminate varieties in the elaboration of the distinction vector and in this way holds the reasonable odds of getting a superior area on the multimodal practical surface. In this way the wellness of the best vector in a populace is a great deal less inclined to get static until a worldwide ideal is come to.

So, the new set of enhanced learners can be made by utilizing comparison as a part of the teacher phase

$$
\mathrm{X}_{\text {new }(\mathrm{i})}^{\mathrm{g}}=\mathrm{X}_{(\mathrm{i})}^{\mathrm{g}}+0.5 *(1+\operatorname{rand}(0,1)) *\left(\mathrm{X}_{\text {Teacher }}^{\mathrm{g}}-\mathrm{T}_{\mathrm{F}} \mathrm{M}^{\mathrm{g}}\right)(2)
$$

So, the new arrangement of enhanced learners can be made by mathematical statement in the learner phase

$$
\left\{\begin{array}{c}
\mathrm{X}_{(\mathrm{i})}^{\mathrm{g}}+0.5 *\left(1+\operatorname{rand}(0,1) *\left(\mathrm{X}_{(\mathrm{i})}^{\mathrm{g}}-\mathrm{X}_{(\mathrm{r})}^{\mathrm{g}}\right) \operatorname{iff}\left(\mathrm{X}_{(\mathrm{i})}^{\mathrm{g}}\right)<\mathrm{f}\left(\mathrm{X}_{(\mathrm{r})}^{\mathrm{g}}\right)\right. \\
\mathrm{X}_{(\mathrm{i})}^{\mathrm{g}}+0.5 *(1+\operatorname{rand}(0,1)) *\left(\mathrm{X}_{(\mathrm{r})}^{\mathrm{g}}-\mathrm{X}_{(\mathrm{i})}^{\mathrm{g}}\right) \text { otherwise }
\end{array}\right\}(3)
$$




\section{Weighted Teaching Learning Based Optimization (wTLBO)}

TLBO depends on the guideline of educating learning approach and a teacher dependably wishes that his/her student ought to accomplish the knowledge equivalent to him in quick conceivable time. Now and again it gets to be troublesome for an understudy to achieve the knowledge because of his/her overlooking qualities. Teaching-learning process is an iterative procedure where persistent collaboration happens for the exchange of knowledge Each time an instructor communicates with a student he/she finds that the student can review the part of the lessons learnt from the last session [23].

In some cases, learner may not be in position to review the knowledge taught in the past session since this is fundamentally because of the physiological marvels of neurons in the mind. Consequently, a parameter known as "weight" is incorporated to each learner. While figuring the new learner esteem the piece of its past worth is considered and that is chosen by a weight factor $\mathrm{w}$.

In wTLBO, every learner is examined to various zone of the hunt space amid the early phases of the inquiry. In the later stages' conformities are done to the developments of trial arrangements finely with the goal that they can investigate the inside of a moderately little space in which the normal global ideal untruths. To meet this target, we lessen the value of the weight factor directly with time from a (foreordained) greatest to a (foreordained) minimum value:

$$
\mathrm{W}=\mathrm{W}_{\max }-\left(\frac{\mathrm{W}_{\max }-\mathrm{W}_{\min }}{\text { maxiteration }}\right) * \mathrm{i}
$$

where max and min are the most extreme and least estimations of weight factor w, I cycle is the present emphasis number and maxiteration is the greatest number of suitable emphases. W maxandWmin are chosen to be 0.9 and 0.1 , separately.

Consequently, in the teacher phase the new arrangement of enhanced learners can be

$$
\left.\mathrm{X}_{\text {new (i) }}^{\mathrm{g}}=\mathrm{W} * \mathrm{X}_{(\mathrm{i})}^{\mathrm{g}}+\text { rand } *\left(\mathrm{X}_{\text {Teacher }}^{\mathrm{g}}-\mathrm{T}_{\mathrm{f}} \mathrm{M}^{\mathrm{g}}\right)\right)
$$

And a set of improved learners in learner phase as

$$
\left\{\begin{array}{c}
\mathrm{w} * \mathrm{X}_{(\mathrm{i})}^{\mathrm{g}}+\operatorname{rand} *\left(\mathrm{X}_{(\mathrm{i})}^{\mathrm{g}}-\mathrm{X}_{(\mathrm{r})}^{\mathrm{g}}\right) \text { if } \mathrm{f}\left(\mathrm{X}_{(\mathrm{i})}^{\mathrm{g}}\right)<\mathrm{f}\left(\mathrm{X}_{(\mathrm{r})}^{\mathrm{g}}\right) \\
\mathrm{w} * \mathrm{X}_{(\mathrm{i})}^{\mathrm{g}}+\text { rand } *\left(\mathrm{X}_{(\mathrm{r})}^{\mathrm{g}}-\mathrm{X}_{(\mathrm{i})}^{\mathrm{g}}\right) \text { otherwise }
\end{array}\right\}
$$

\section{Orthogonal Teaching-Learning-Based Optimization (oTLBO)}

Consider an investigation that includes a few elements, each of which have a few conceivable qualities called levels. Assume that there are $\mathrm{P}$ factors, every factor has $\mathrm{Q}$ levels. The quantity of blends is $\mathrm{Q}^{\mathrm{P}}$, and for vast $\mathrm{P}$ and $\mathrm{Q}$ it is not functional to assess all mixes [24].

Orthogonal configuration is produced as a numerical tool to contemplate multi- factor and multi-level issues. It expects to separate an orthogonal cluster L if M row, where every column speaks to a blend to be assessed. The array has three key properties.

1. Amid the examination, the array speaks to a subset of $\mathrm{M}$ combinations from all conceivable $\mathrm{Q}^{\mathrm{P}}$ combinations. Computation is diminished impressively in light of the fact that $\mathrm{M}<<\mathrm{Q}^{\mathrm{P}}$.

2. Every segment speaks to a variable. In the event that a few segments are erased from the array, it implies a littler number of factors are considered.

3. The sections of the exhibit are orthogonal to one another. The chose subset is scattered consistently over the search space to ensure its assorted qualities.

\section{E. CooperativeTeaching-Learning-Based Optimization (CoTLBO)}

To improvise the execution of every individual competitionought to be available among the learners Consequently, we partition the learners into groups and conduct rivalries among them. Rather than streamlining the entire arrangement vector in one populace, the vector is part into its constituent segments and allocated to different GA populaces. In this design, every populace is then streamlining a solitary part of the arrangement vector as one-dimensional (1-D) optimization issue. To deliver an answer vector for the capacity being minimized every one of the populaces need to participate, as a legitimate arrangement vector must be shaped by utilizing data from every one of the populations. This implies on top of the characteristic participation in the populace itself, another layer of collaboration between populaces are added [25].

The same idea is connected to TLBO, by making a group of CoTLBO. Rather than having one class (of N learners) attempting to locate the optimal D-dimensional vector, the vector is part into its segments so that classes (of $\mathrm{N}$ learners each) are optimizing a 1-D vector. 
Vol. 8, Issue 2, February 2019

\section{F. Modified Teaching-Learning-Based Optimization (mTLBO)}

In this modification is done just to the learner phase of essential TLBO. The Teacher phase stays same as in unique. Through the comprehensive investigation of TLBO idea, it is unmistakably obvious that the more the learner learns in the better the arrangement. In a conventional teaching-learning environment the learners output relies on upon the collaboration in the middle of learners and the classroom conveyance by teachers. To further upgrade the learning capacity of understudies an additional preparing through thetutorial helps. Group discussions, presentations, formal interchanges and so forth give a right platform to the learners to associate with their companions however arbitrarily, and in the meantime he or she can examine intricately with the teacher who is better knowledgeable person in a tutorial class. A learner dependably gains some new useful knowledge from the teacher and if the other learner has more knowledge than him or her then just he or she gets more knowledge. Thus, an additional term has been included the learner phase comparison to modify TLBO[26]. Enlivened by the idea to Differential Evolution with Random Scale Factor (DERSF) this term is scaled by scale component in a random manner in the extent $(0.5,1)$ by utilizing.

$$
0.5 *(1+\operatorname{rand}(0,1))
$$

Where, rand $(0,1)$ is a consistently appropriated random number inside of the range [0,1]. The mean estimation of the scale component is 0.75 . This takes into account stochastic varieties in the accessible arrangements and hence holds learner differences as the pursuit advances. Even when the vast majority of the hopeful arrangements point to areas grouped close to a nearby ideal, this term gives a reasonable shot of indicating at a far and away superior area on the multi modal functional surface. In this way the wellness of the best arrangement in a populace is a great deal less inclined to get stagnant until a global optimum ideal is come to.

\section{TLBO PHASES}

Underneath we quickly examine the execution of TLBO.

\section{1) Initialization:}

Taking after are the documentations utilized for portraying the TLBO

$\mathrm{N}$ : number of learners in class i.e. "class size"

D: number of courses offered to the learners

MAXIT: most extreme number of passable emphases

The populace $\mathrm{X}$ is haphazardly instated by an inquiry space limited by lattice of $\mathrm{N}$ rows and $\mathrm{D}$ columns. The jth parameter of the ith learner is allocated values haphazardly utilizing the equation

$$
\mathrm{x}_{(\mathrm{i}, \mathrm{j})}^{0}=\mathrm{x}_{\mathrm{j}}^{\min }+\operatorname{rand} *\left(\mathrm{x}_{\mathrm{j}}^{\max }-\mathrm{x}_{\mathrm{j}}^{\min }\right)
$$

where rand speaks to a consistently appropriated arbitrary variable inside of the extent $\left(0,1 x_{j}^{\min ^{2}}\right.$ andx $_{j}^{\text {max }}$ the minimum and maximum value for $\mathrm{j}^{\text {th }}$ parameter. The parameters of $\mathrm{i}^{\text {th }}$ learner for the era $\mathrm{g}$ are given by

$$
\mathrm{aX}_{(\mathrm{i})}^{\mathrm{g}}=\left[\mathrm{x}_{(\mathrm{i}, 1)}^{\mathrm{g}}, \mathrm{x}_{(\mathrm{i}, 2)}^{\mathrm{g}} \ldots, \mathrm{x}_{(\mathrm{i}, \mathrm{j})}^{\mathrm{g}}, \ldots, \mathrm{x}_{(\mathrm{i}, \mathrm{D})}^{\mathrm{g}}\right]
$$

\section{2) Teacher Phase:}

The mean parameter $\mathrm{Mg}$ of every subject of the learners in the class at generation $\mathrm{g}$ is given as

$$
\mathrm{M}^{\mathrm{g}}=\left[\mathrm{m}_{1}^{\mathrm{g}}, \mathrm{m}_{2}^{\mathrm{g}}, \ldots, \mathrm{m}_{\mathrm{j}}^{\mathrm{g}}, \ldots, \mathrm{m}_{\mathrm{D}}^{\mathrm{g}}\right]
$$

The learner with the base target capacity quality is considered as the teacher Xg Teacher for separate cycle. The Teacher phase makes the algorithm continue by moving the mean of the learners towards its teacher. To acquire another arrangement of enhanced learners an arbitrary weighted differential vector is framed from the present mean and the craved mean parameters and added to the current populace of learners.

$$
\mathrm{Xnew}_{(\mathrm{i})}^{\mathrm{g}}=\mathrm{X}_{(\mathrm{i})}^{\mathrm{g}}+\operatorname{rand} *\left(\mathrm{X}_{\text {teacher }}^{\mathrm{g}}-\mathrm{T}_{\mathrm{F}} \mathrm{M}^{\mathrm{g}}\right)(11)
$$

TF is the teaching component which chooses the estimation of intend to be changed. Value of TF can be either 1 or 2. The estimation of TF is chosen arbitrarily with equivalent likelihood as,

where TF is not a parameter of the TLBO algorithm.

$$
\mathrm{T}_{\mathrm{F}}=\operatorname{round}[1+\operatorname{rand}(0,1)\{2-1\}]
$$

The estimation of TF is not given as a input to the algorithm and its worth is arbitrarily chosen by the algorithm utilizing Eq. (12). Subsequent to leading various examinations on numerous benchmark capacities it is reasoned that 
Vol. 8, Issue 2, February 2019

the calculation performs better if the estimation of $\mathrm{TF}$ is somewhere around 1 and 2. Be that as it may, the calculation is found to perform vastly improved if the estimation of TF is either 1 or 2 and subsequently to disentangle the algorithm, the teaching factor is recommended to take either 1 or 2 relying upon the gathering together criteria given by Eq(5). If $\mathrm{Xnew}_{(\mathrm{i})}^{\mathrm{g}}$ is observed to be predominant learner than $\mathrm{X}_{(\mathrm{i})}^{\mathrm{g}}$ in era $\mathrm{g}$, than it replaces inferior learner $\mathrm{X}_{(\mathrm{i})}^{\mathrm{g}}$ in the matrix.

\section{3) Learner Phase:}

In this phase the cooperation of learners with each other happens. The procedure of shared association tends to expand the knowledge of the learner. The random connection among learners enhances his or her knowledge. For a given learner $\mathrm{X}_{(\mathrm{i})}^{\mathrm{g}}$, another learner $\mathrm{X}_{(\mathrm{r})}^{\mathrm{g}}$ is haphazardly chose $(\mathrm{i} \neq \mathrm{r})$. The $\mathrm{i}^{\text {th }}$ parameter of the matrix Xnew in the learner phase is given as

$$
\left\{\begin{array}{c}
\mathrm{X}_{(\mathrm{i})}^{\mathrm{g}}+\operatorname{rand} *\left(\mathrm{X}_{(\mathrm{i})}^{\mathrm{g}}-\mathrm{X}_{(\mathrm{r})}^{\mathrm{g}}\right) \operatorname{iff}\left(\mathrm{X}_{(\mathrm{i})}^{\mathrm{g}}\right)<\mathrm{f}\left(\mathrm{X}_{(\mathrm{r})}^{\mathrm{g}}\right) \\
\mathrm{X}_{(\mathrm{i})}^{\mathrm{g}}+\operatorname{rand} *\left(\mathrm{X}_{(\mathrm{r})}^{\mathrm{g}}-\mathrm{X}_{(\mathrm{i})}^{\mathrm{g}}\right) \text { otherwise }
\end{array}\right\}
$$

\section{4) Algorithm Termination:}

The algorithm is ended after MAXIT emphases are finished.

\section{COMPARISON BETWEEN VARIOUS TLBO}

\begin{tabular}{|c|c|c|c|}
\hline & Concept & Merits & Demerits \\
\hline $\begin{array}{l}\text { Improved Teaching } \\
\text { Learning Based } \\
\text { Optimization }\end{array}$ & $0.5 *(1+\operatorname{rand}(0,1))$ & $\begin{array}{l}\text { 1. The random number is } \\
\text { supplanted by this worth } \\
\text { accordingly prompting } \\
\text { better security. }\end{array}$ & $\begin{array}{l}\text { 1. It has included just } \\
\text { a few factors only. }\end{array}$ \\
\hline $\begin{array}{l}\text { Weighted Teaching } \\
\text { Learning Based } \\
\text { Optimization }\end{array}$ & $\mathrm{W}=\mathrm{W}_{\max }-\left(\frac{\mathrm{W}_{\max }-\mathrm{W}_{\min }}{\text { maxiteration }}\right) * \mathrm{i}$ & $\begin{array}{l}\text { 1. The idea of weighted } \\
\text { qualities is utilized. }\end{array}$ & $\begin{array}{l}\text { 1. The qualities } \\
\text { having weights are } \\
\text { obligatory. }\end{array}$ \\
\hline $\begin{array}{l}\text { Orthogonal } \\
\text { Teaching-Learning- } \\
\text { Based Optimization }\end{array}$ & $\begin{array}{l}\text { Multi-factor and multi-level } \\
\text { problems }\end{array}$ & $\begin{array}{l}\text { 1. Themulti-variable } \\
\text { qualities are considered. } \\
\text { 2. Orthogonal clusters are } \\
\text { made. }\end{array}$ & $\begin{array}{l}\text { 1. Erasure of few } \\
\text { exhibits might prompt } \\
\text { cancellation of } \\
\text { essential qualities. }\end{array}$ \\
\hline $\begin{array}{l}\text { Cooperative } \\
\text { Teaching-Learning- } \\
\text { Based Optimization }\end{array}$ & Multiple GA are assigned & $\begin{array}{l}\text { 1. The utilization of } \\
\text { various GAs are utilized. } \\
\text { 2. Optimized results are } \\
\text { acquired. }\end{array}$ & 1. Complexity is high. \\
\hline $\begin{array}{l}\text { Modified Teaching- } \\
\text { Learning-Based } \\
\text { Optimization }\end{array}$ & $\begin{array}{l}\text { Exhaustive analysis of TLBO } \\
\text { concept }\end{array}$ & $\begin{array}{l}\text { 1. Continually something } \\
\text { new is learned by learner. }\end{array}$ & $\begin{array}{l}\text { 1. Extra training is } \\
\text { required. }\end{array}$ \\
\hline
\end{tabular}

\section{CONCLUSION}

Multi-objective optimization emerged as a significant research area in engineering studies because most of the realworld problems require optimization with a group of objectives. The most recently developed meta-heuristics called the teaching-learning-based optimization (TLBO) and its variant algorithms belongs to this category. This paper is all about teaching learning based optimization. There are many alternatives algorithm for the enhancement over TLBO. Here TLBO phases have also defined.

\section{REFERENCES}

[1]. Dr. Sudhir B. Jagtap, “Census Data Mining and Data Analysis using WEKA", International Conference in "Emerging Trends in Science, Technology and Management-2013.

[2]. Mitchell, "An Introduction to Genetic Algorithms", MIT Press, 1996.

[3]. Kennedy, J., Eberhart, R.C.: Particle Swarm Optimization. In Proceeding of IEEE International Conference on Neural Network. IEEE Press, 1995.

[4]. Karaboga, D., Basturk, "On the performance of artificial bee colony algorithm”, Applied Soft Computing 8(1), 2008 , pp. 687-697.

[5]. Lhotská, L., Macaš, M., Burša, "PSO and ACO in Optimization Problems", In Corchado, E., Yin, H., Botti, V., Fyfe, C. (eds.) IDEAL,Springer, Heidelberg, LNCS, vol. 4224, 2006, pp. 1390-1398.

[6]. Geem, Z.W., Kim, J.H., Loganathan, G.V.,"A new heuristic optimization: harmony search”, Simulation 76, 2001 , pp. 60-70.

[7]. Venkata Rao, R., Patel, "An elitist teaching-learning-based optimization algorithm for solving complex constrained optimization problems", International Journal of Industrial Engineering Computations 3, 2012, pp. 535-560. 


\title{
International Journal of Advanced Research in Computer and Communication Engineering
}

\author{
Vol. 8, Issue 2, February 2019
}

[8]. Baghlani, A., Makiabadi, M.H.,"Teaching-Learning-Based Optimization Algorithm for Shape and Size Optimization of Truss Structures With Dynamic Frequency Constraints", IJST 37(C+), 2013, pp. 409-42.

[9]. A. Baghlani, et. al., "Teaching-learning-based optimization algorithm for shape And size optimization of truss structures with Dynamic frequency constraints", IJST, Transactions of Civil Engineering, Vol. 37, No. C+, 2013, pp 409-421.

[10]. Kailin Wang et. al., "Teaching-Learning-Based Optimization Algorithm for Dealing with Real-Parameter Optimization Problems", Applied Mechanics and Materials Vols 380-384, 2013, pp. 1342-1346.

[11]. Anguluri Rajasekhar et. al., "Elitist Teaching Learning Opposition based Algorithm for Global Optimization", 2012 IEEE International Conference on Systems, Man, and Cybernetics (SMC), 2012, pp. 1124-1129.

[12]. Shakil Ahmed, Frans Coenen, Paul Leng, "Tree based partitioning of data for association rule mining", Knowledge Information System, 2006.

[13]. Chandra Satapathy, Anima Naik, K. Parvathi, "Weighted Teaching-Learning-Based Optimization for Global Function Optimization", Applied Mathematics, 2013, 4, 429-439.

[14]. G. Wadhmare, “Comments on A note on teaching-learning-based optimization algorithm”,Information Sciences, vol. 229, 2013 , pp. 159-169.

[15]. K.R. Krishnanand,"Application of Multi-Objective Teaching-Learning-Based Algorithm to an Economic Load Dispatch Problem with Incommensurable Objectives”, SEMCCO, LNCS, vol. 7076, 2011, pp. 697-705.

[16]. R.V. Rao and V. Patel, "Multi-objective optimization of combined Brayton and inverse Brayton cycles using advanced optimization algorithms", Engineering Optimization, Vol. 44, 2012, pp. 965-983.

[17]. R.V. Rao, et al, - Teaching-learning-based optimization: A novel method for constrained mechanical design optimization problems, Computer-Aided Design, vol. 43, 2011, pp. 303-315.

[18]. A. Rajasekhar, et al, -Elitist Teaching Learning Opposition based Algorithm for Global Optimization, IEEE International Conference on Systems, Man, and Cybernetics, 2012, pp. 1124-1129.

[19]. Rao, R.V., Savsani, V.J. and Vakharia, D.P. "Teaching-learning-based optimization:a novel method for constrained mechanical design optimizationproblems", Comput. Aided Des., 43(3), 2011, pp. 303-315.

[20]. Rao, R.V., Savsani, V.J. and Vakharia, D.P. "Teaching-learning-basedoptimization: a novel optimization method for continuous nonlinearlarge scale problems", Inform. Sci., 183(1), 2011, pp. 1-15.

[21]. Rao, R.V. and Patel, V. "An elitist teaching-learning-based optimizationalgorithm for solving complex constrained optimization problems", Int. J.Ind. Eng. Comput., 3(4), 2012, pp. 535-560.

[22]. Venkata Rao, R., Patel, V.,"An improved teaching-learning-based optimization algorithm for solving unconstrained optimization problems", Scientia Iranica, 2013.

[23]. Satapathy, S.C., Naik, A.,“A Weighted teaching learning based optimization for global function optimization”, Applied Mathematics 4, 2013, pp. 429-439.

[24]. Satapathy, S.C., Naik, A.,“A A teaching learning based on orthogonal design for solving global optimization problems”, Spinger Plus Journal 2, $130,2013$.

[25]. Zheng, H.-Y., Wang, L., Wang, S.-Y.,“A Co-evolutionary Teaching-learning based Optimization Algorithm for Stochastic RCPSP”, In IEEE Congress on Evolutionary Computation, CEC, 2014.

[26]. Satapthy, S.C., Naik, A.,"A Modified Teaching-Learning-Based Optimization algorithm for global numerical optimization-A comparative study", Swarm and Evolutionary Computation 16, 2014, pp. 28-37. 